Check for updates

Cite this: RSC Adv., 2018, 8, 12951

Received 14th February 2018

Accepted 21st March 2018

DOI: $10.1039 / \mathrm{c} 8 \mathrm{ra01407h}$

rsc.li/rsc-advances

\title{
Preparation and physicochemical characterization of camptothecin conjugated poly amino ester- methyl ether poly ethylene glycol copolymer
}

\author{
Ali Fattahi, ${ }^{a}$ Nadia Karimi, ${ }^{\text {ab }}$ Fatemeh Rahmati, ${ }^{c}$ Yalda Shokoohinia ${ }^{d}$ \\ and Komail Sadrjavadi iD *d
}

In the present study, camptothecin grafted poly amino ester-methyl ether polyethylene glycol (CPT-PEAMPEG) as a novel copolymer was synthesized by Michael reaction at different ratios of MPEG and CPT (60: 40 and $80: 20$ ). The microemulsion was used to prepare nanomicelles, and in vitro cytotoxicity was performed on the HT29 cell line, and cell survival was measured by MTT assay. The syntheses were confirmed by ${ }^{1} \mathrm{H}$ NMR and FT-IR. Several characterization methods including CMC, particle size, size distribution, and transmission electron microscopy were performed to evaluate features of prepared nanomicelles. Low critical micelle concentration, small particle size and $I_{50}$ of $0.1 \mathrm{mg} \mathrm{ml}^{-1}$ at MPEG to CPT ratio of $60: 40$ make this micelle a promising drug delivery carrier. CPT-PAE-MPEG nanomicelles at a MPEG : CPT ratio of $60: 40$ can be a suitable choice to improve the physiochemical properties of CPT and its therapeutic effect, while it can be potentially used as a nano-carrier for other anticancer drugs to purpose a dual drug delivery.

\section{Introduction}

Cancer is one of the most devastating diseases causing huge mortality around the world. Current cancer therapy suffers from some vital drawbacks such as non-specific targeting, drug resistance, poor bioavailability, low solubility in water, and also toxicity for normal cells resulting in patient toxicity. Nano drug delivery systems, e.g., polymeric nanoparticles, nanomicelles, and polymersomes are promising candidates to overcome such drawbacks and provide selective drug delivery which possesses the ability to be designed for optimal size and surface characteristics. ${ }^{\mathbf{1 , 2}}$

Polymeric micelles introduced as drug delivery vehicles in the 1980 s by Helmut Ringsdorf and co-workers ${ }^{3}$ have manifested several advantages over other types of carrier. Their core-shell structure with the drug in the core guarantees low toxicity in the human body, and their prolonged circulation time in the bloodstream is owing to the high hydrophilic shell which prevents phagocytic and renal clearance. ${ }^{4}$ Furthermore,

${ }^{a}$ Medical Biology Research Center, Kermanshah University of Medical Sciences, Kermanshah, Iran

${ }^{b}$ Department of Chemistry, Basic of Sciences Faculty, Ilam University, Ilam, Iran

${ }^{c}$ Student Research Committee, School of Pharmacy, Kermanshah University of Medical Sciences, Kermanshah, 6734667149, Iran

'Pharmaceutical Sciences Research Center, School of Pharmacy, Kermanshah University of Medical Sciences, Kermanshah, 6734667149, Iran. E-mail: komail. sadrjavadi@gmail.com they possess proper stability, bioavailability and strong mechanical properties. ${ }^{5}$

Recently, co-delivery of small molecule anticancer drugs, macromolecular genes and therapeutic proteins has attracted more attention. ${ }^{6,7}$ Accordingly, different types of polymeric micelles were used for co-delivery of drugs and genes. ${ }^{8-10}$ Among dual drug delivery systems, drug conjugated polymeric micelles were more interesting because the hydrophobic drugs play two main roles simultaneously as hydrophobic apart of micelles and efficient drug. ${ }^{11-13}$

Poly amino ester is a biodegradable and biocompatible cationic polymer easily synthesized from primary amines and diacrylate esters. ${ }^{\mathbf{1 4 , 1 5}}$ It has the high buffer capacity due to its tertiary amine groups ${ }^{\mathbf{1 6}}$ and has been used excessively in drug and gene delivery. ${ }^{17}$

Polyethylene glycol (PEG) is one of the most suitable polymers used for biotechnological and biomedical applications. Due to the high hydrophilic properties, solubility in aqueous and organic solvents and absence of antigenicity and immunogenicity, it is utilized for hydrophilic outer shell in preparation of polymeric micelles. ${ }^{18}$ Although adding PEG or any other hydrophilic polymer into the structure of the nano-particular system can reduce cell uptake, this disadvantage can be justified by using specific ligands, e.g., monoclonal antibodies and aptamers. Camptothecin is a five-ring alkaloid and a topoisomerase inhibitor, effective on a wide range of tumors. It has a limited therapeutic application due to its instability at neutral $\mathrm{pH}$, low solubility in aqueous medium and nephrotoxicity. Polymeric micelles are among novel pharmaceutical carriers 
widely used to minimize or eliminate undesired physiochemical characteristics of CPT. ${ }^{19}$

The aim of the present study is the synthesis of a new generation of polymeric micelles with inherent anticancer activity by synthesis of CPT-PAE-MPEG copolymer and preparation of its micelles.

\section{Materials and methods}

\section{Materials}

1,6-hexanediol diacrylate, 6-bromohexanoic acid, 4-toluenesulfonyl chloride (Tos-Cl), propargylamine, sodium azide $\left(\mathrm{NaN}_{3}\right), N, N^{\prime}$-dicyclohexylcarbodiimide (DCC) and 4-dimethyl aminopyridine (DMAP) were purchased from Sigma [St. Louis, MO, USA]. Methoxy poly (ethylene glycol) [MPEG; numberaverage molecular weight $\left(M_{\mathrm{n}}\right)=2000$, Sigma-Aldrich] was dried over anhydrous toluene by azeotropic distillation. Dimethylsulfoxide (DMSO), diethyl ether, methanol $(\mathrm{MeOH})$, chloroform $\left(\mathrm{CCl}_{3}\right)$, dimethylformamide (DMF), tetrahydrofuran (THF), ethyl acetate (EtOAc), toluene, and acetone [Merck A.G., Germany] included in the polymerization recipe as a diluent were used without further purification. Dichloromethane (DCM) was obtained from Merck and dried by refluxing over calcium hydride at $60{ }^{\circ} \mathrm{C}$ for two $\mathrm{h}$, and it was distilled immediately before use. Mineral materials, e.g., $\mathrm{CuBr}, \mathrm{CaCl}_{2}, \mathrm{NaCl}$, and $\mathrm{NaHCO}_{4}$, were purchased from Merck, Germany.

\section{Methods}

\section{Synthesis of MPEG-N $\mathbf{N}_{3}$}

Synthesis of MPEG-Tos. MPEG-N $\mathrm{N}_{3}$ was synthesized in two steps; at first, MPEG $(2 \mathrm{~g}, 1 \mathrm{mmol})$ was dissolved in $15 \mathrm{ml}$ of DCM and triethylamine $(2.78 \mathrm{ml}, 20 \mathrm{mmol})$. Then DMAP $(1.22 \mathrm{~g}$, $10 \mathrm{mmol})$ and Tos-Cl $(1.91 \mathrm{~g}, 10 \mathrm{mmol})$ were added to the mixture. The reaction mixture was stirred for $24 \mathrm{~h}$ at room temperature under a nitrogen atmosphere (Fig. 1A). Finally, hydrochloric acid $(4 \mathrm{M})$ was added, and the reaction mixture was washed thrice with $100 \mathrm{ml}$ of acid, and the residue was dried using anhydrous $\mathrm{CaCl}_{2}$, followed by filtration to remove the salt. The evaporation of the solvent was carried out in vacuum. The resulting product was purified using column chromatography over silica gel; at first, with $\mathrm{CH}_{2} \mathrm{Cl}_{2} /$ EtOAc mixture (ratio of $1: 1$ ) and then with $\mathrm{MeOH} / \mathrm{CH}_{2} \mathrm{Cl}_{2}$ mixture (ratio of $1: 10$ ). The resulting product was dissolved in tetrahydrofuran (THF), precipitated in cold diethyl ether, and dried in a vacuum oven ( $85 \%$ yield). ${ }^{20}$ The synthesis was proved using FT-IR.

FT-IR $(\mathrm{KBr}): \nu_{\max }\left(\mathrm{cm}^{-1}\right)=3069(=\mathrm{C}-\mathrm{H}), 2935$ and 2885 $(-\mathrm{C}-\mathrm{H}), 1597$ and $1465(\mathrm{C}=\mathrm{C}$, ring $), 1346(\mathrm{~S}=\mathrm{O}), 1141$ and 1114 (C-O), 842 and 775 (S-O).

Synthesis of MPEG- $\mathrm{N}_{3}$. MPEG-Tos $(500 \mathrm{mg}, 0.25 \mathrm{mmol})$ was dissolved in minimum DMF (less than $15 \mathrm{ml}$ ), and then $\mathrm{NaN}_{3}$ ( $6.6 \mathrm{mg}, 0.1 \mathrm{mmol}$ ) was added. The reaction mixture was stirred for $24 \mathrm{~h}$ at room temperature under the nitrogen atmosphere (Fig. 1B). After evaporation of the solvent in vacuum, the precipitate was dissolved in DCM $(100 \mathrm{ml})$. The solution was washed thrice with $\mathrm{NaCl}(5 \%)$ and distilled water. The solvent was evaporated in vacuum, and it was precipitated in cold diethyl ether. The product was dried in a vacuum oven $(85 \%$ yield). Structure of MPEG- $\mathrm{N}_{3}$ was proved by FT-IR. ${ }^{21}$

FT-IR $(\mathrm{KBr}): \nu_{\max }\left(\mathrm{cm}^{-1}\right)=2935$ and $2885(-\mathrm{C}-\mathrm{H}), 2100\left(-\mathrm{N}_{3}\right)$, 1465 (C-N), 1141 and 1114 (C-O).

Synthesis of camptothecin-azide. CPT- $\mathrm{N}_{3}$ was synthesized in two steps.

Synthesis of 6-azidohexanoic acid. 6-bromohexanoic acid $(500 \mathrm{mg}, 2.56 \mathrm{mmol})$ and $\mathrm{NaN}_{3}(420 \mathrm{mg}, 6.4 \mathrm{mmol})$ were added to a reaction flask and dissolved in DMSO $(20 \mathrm{ml})$. The reaction mixture was stirred for $24 \mathrm{~h}$ at room temperature under nitrogen atmosphere. Then, the reaction mixture was washed with $\mathrm{CH}_{2} \mathrm{Cl}_{2}(30 \mathrm{ml})$, and the organic layer was separated and washed three times with $\mathrm{NaCl}(26 \%)$ and distilled water. Again, the resulting mixture was washed with saturated aqueous $\mathrm{NaHCO}_{3}$ and dried with anhydrous $\mathrm{CaCl}_{2}$. The final 6-azidohexanoic acid was obtained (25\% yield) after removing the solvent. The reaction is shown in Fig. 1C, and structure of the product was proved by FT-IR and ${ }^{1} \mathrm{H}$ NMR spectroscopy.

FT-IR (KBr): $\nu_{\max }\left(\mathrm{cm}^{-1}\right)=2500-3400(\mathrm{OH}), 2959$ and 2868 $(-\mathrm{C}-\mathrm{H}), 2096\left(-\mathrm{N}_{3}\right), 1708(\mathrm{C}=\mathrm{O}) 1458(\mathrm{C}-\mathrm{N}), 1257(\mathrm{C}-\mathrm{O})$.

${ }^{1} \mathrm{H}$ NMR (400 MHz; DMSO-d $\left.{ }_{6}\right): \delta=1.32(\mathrm{t}, 2 \mathrm{H}), 1.49,2.21$ $\left(2 \mathrm{~m}, 4 \mathrm{H}, 2 \mathrm{CH}_{2}\right), 2.54\left(\mathrm{t}, 2 \mathrm{H}, \mathrm{CH}_{2} \mathrm{C}=\mathrm{O}\right), 3.32\left(\mathrm{t}, 2 \mathrm{H}, \mathrm{CH}_{2}-\mathrm{N}_{3}\right)$, 11.88 (brs, $1 \mathrm{H}, \mathrm{OH})$.

Synthesis of camptothecin-azide. The CPT- $\mathrm{N}_{3}$ was synthesized by the reaction between CPT $(100 \mathrm{mg}, 0.27 \mathrm{mmol})$ with azidohexanoic acid ( $85 \mathrm{mg}, 0.54 \mathrm{mmol})(4 \mathrm{mg}, 0.03 \mathrm{mmol})$ in dry $\mathrm{CH}_{2} \mathrm{Cl}_{2}$ and at the presence of DMAP/DCC. ${ }^{22}$ CPT, azidohexanoic acid, DMAP, and $\mathrm{CH}_{2} \mathrm{Cl}_{2}(5 \mathrm{ml})$ were added to a reaction bottle. The reaction mixture was cooled down to $0{ }^{\circ} \mathrm{C}$, and DCC $(110 \mathrm{mg}, 0.54 \mathrm{mmol})$ was added. The reaction mixture was stirred for $2 \mathrm{~h}$ under nitrogen atmosphere. Then the mixture reaction was stirred at room temperature for $6 \mathrm{~h}$. The product was precipitated, and it was crystallized from a Me-OH/DCM mixture (with a ratio of $95: 5$ ). For this purpose, the reaction mixture was kept at a temperature in the range of $30-40{ }^{\circ} \mathrm{C}$ for $30 \mathrm{~min}$ until a clear solution was obtained. Then, the solution was kept at a temperature of $0{ }^{\circ} \mathrm{C}$ overnight until $\mathrm{CPT}-\mathrm{N}_{3}$ precipitate was obtained. The product was dissolved in $\mathrm{CHCl}_{3}$ and was centrifuged at $8800 \mathrm{rpm}$ for $20 \mathrm{~min}$. The solution was separated and was dried in vacuum ( $45 \%$ yield). ${ }^{23}$ Structure of CPT- $\mathrm{N}_{3}$ was proved by FT-IR and ${ }^{1} \mathrm{H}$ NMR data. The reaction is shown in Fig. 1D.

FT-IR $(\mathrm{KBr}): \nu_{\max }\left(\mathrm{cm}^{-1}\right)=3082(=\mathrm{C}-\mathrm{H}, \mathrm{ring}), 2939$ and 2870 $(-\mathrm{C}-\mathrm{H}), 2100\left(-\mathrm{N}_{3}\right), 1728(\mathrm{C}=\mathrm{O}$ of ester $), 1747(\mathrm{C}=\mathrm{O}$ of lactone), $1666(\mathrm{C}=\mathrm{O}$ of amide $) 1562$ and $1454(\mathrm{C}=\mathrm{C}$ ring $), 1624(\mathrm{C}=\mathrm{N})$, 1346 (C-N), 1230 and 1149 (C-O, ring), 1118 (C-O).

${ }^{1} \mathrm{H}$ NMR (400 MHz; DMSO-d $\left.{ }_{6}\right): \delta=0.99$ (t, $\mathrm{CH}_{3}$, aliphatic), $1.91\left(\mathrm{t}, 2 \mathrm{H}, \mathrm{CH}_{2}\right), 1.38-1.61,\left(\mathrm{~m}, \mathrm{CH}_{2}\right.$, aliphatic), $2.33(\mathrm{t}, 2 \mathrm{H}$, $\mathrm{CH}_{2} \mathrm{C}=\mathrm{O}$ ), $2.5\left(\mathrm{t}, 2 \mathrm{H}, \mathrm{CH}_{2}-\mathrm{N}_{3}\right), 2.96,3.17$ (s, 2H, $\mathrm{CH}_{2}-\mathrm{N}$, ring), 4.29 (s, $2 \mathrm{H}, \mathrm{CH}_{2}-\mathrm{O}$, ring), 5.76-7.72 (m, 6H, $\mathrm{CH}$ of ring).

Synthesis of poly amino ester. PAE was synthesized via Michael addition reaction..$^{24}$ 1,6-Hexanediol diacrylate $(1.15 \mathrm{ml}$, $3.23 \mathrm{mmol})$ and propargylamine $(0.416 \mathrm{ml}, 6.47 \mathrm{mmol})$ were added into a brown reaction vial, far from the light, under solvent-free condition (Fig. 1E). The mixture was stirred for 7 days at room temperature under nitrogen atmosphere. After 7 


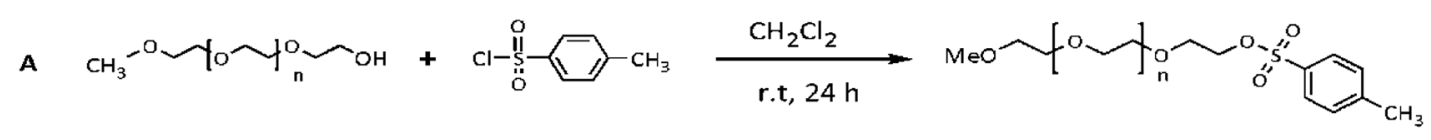

B

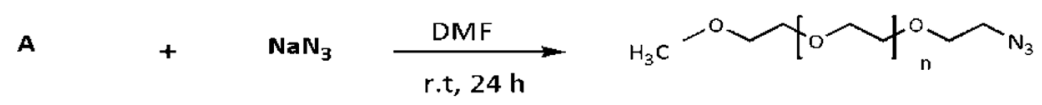

$c$
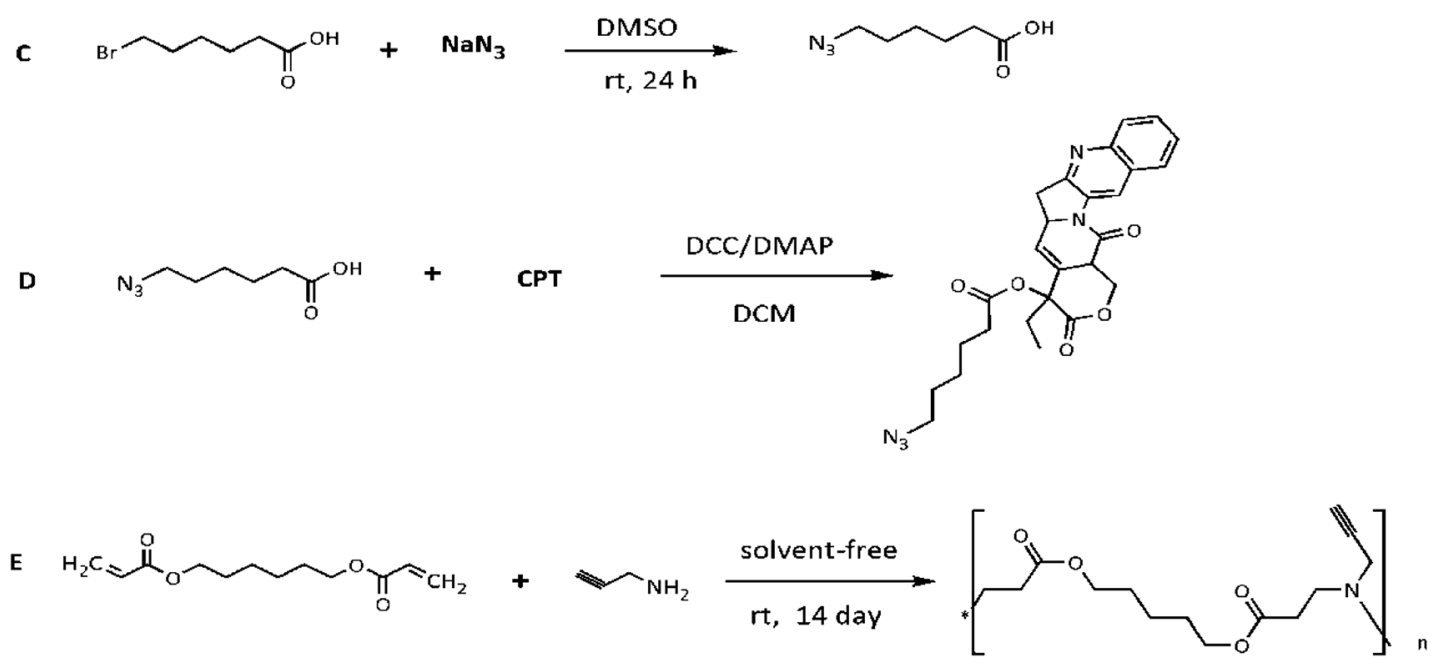

F
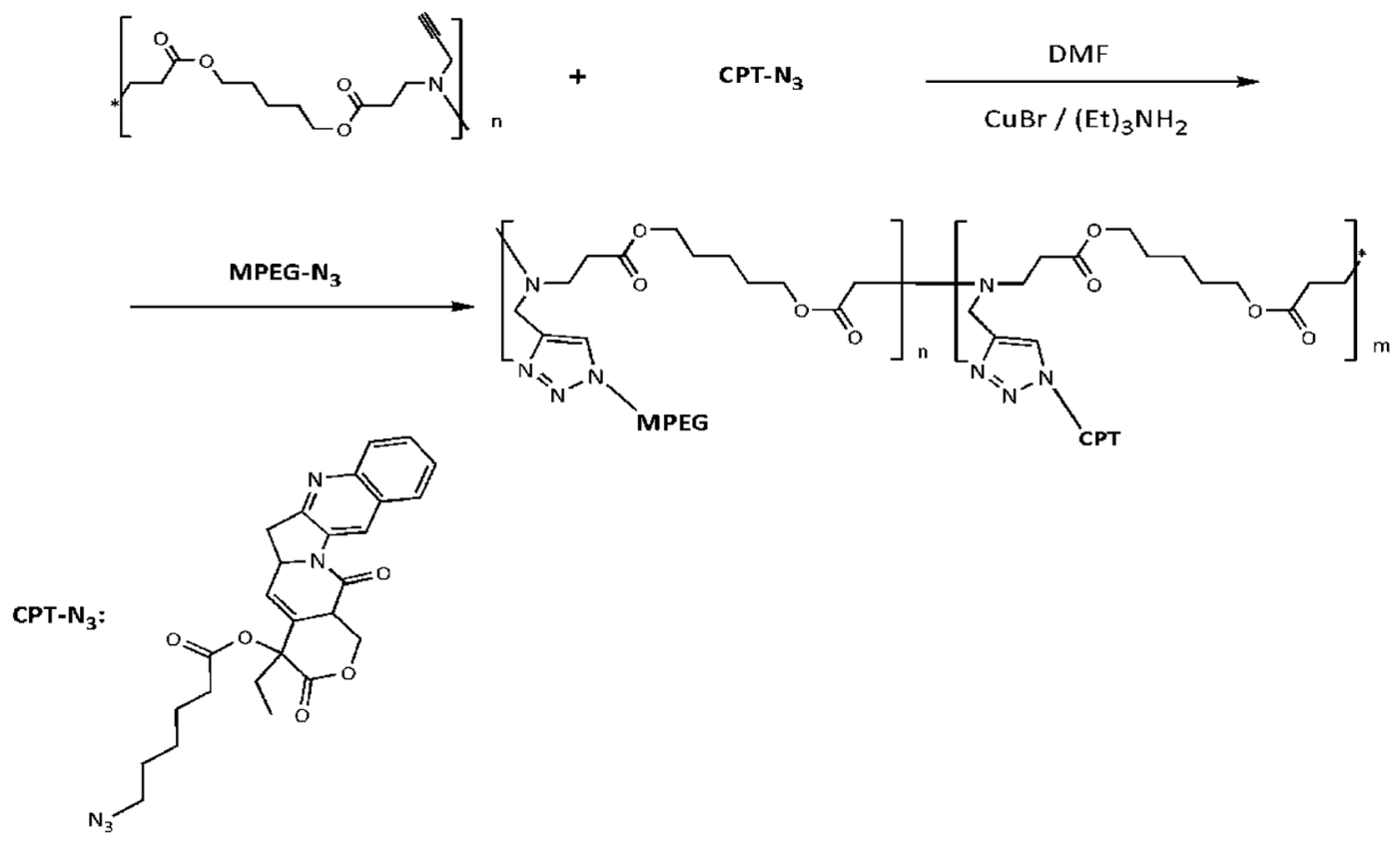

Fig. 1 Schematic of synthesis of MPEG-Tos (A), MPEG-N $(B), 6$-azidohexanoic acid (C), camptothecin-azide (D), poly amino ester (E) and CPTPAE-MPEG copolymer (F).

days, an excess of propargylamine $(0.04 \mathrm{ml}, 0.6 \mathrm{mmol})$ was added to consume any unreacted 1,6-hexanediol, and stirring was continued for further 7 days at $25{ }^{\circ} \mathrm{C}$. The product was precipitated in cold diethyl ether. The solid residue was separated and was dried with vacuum to obtain the product (with a yield of $95 \%$ ). Structure of PAE was proved by FT-IR and ${ }^{1} \mathrm{H}$ NMR data.
FT-IR $(\mathrm{KBr}): \nu_{\max }\left(\mathrm{cm}^{-1}\right)=3444(-\mathrm{N}-\mathrm{H}), 3278(\equiv \mathrm{C}-\mathrm{H}), 2927$ and $2857(-\mathrm{C}-\mathrm{H}), 2102(-\mathrm{C} \equiv \mathrm{C}), 1728(\mathrm{C}=\mathrm{O}$ of ester $), 1462(-\mathrm{N}-$ $\mathrm{H}), 1327$ (C-N), 1257 (C-O), 732 (-N-H, oop).

${ }^{1} \mathrm{H}$ NMR (400 MHz; DMSO-d $\left.\mathrm{d}_{6}\right): \delta=1.27,1.39,1.64(\mathrm{~m}, 12 \mathrm{H}$, $\mathrm{CH}_{2}$, aliphatic), $2.22(\mathrm{~s}, 1 \mathrm{H},-\mathrm{C} \equiv \mathrm{C}-\mathrm{H}), 2.54\left(\mathrm{t}, 2 \mathrm{H}, \mathrm{CH}_{2} \mathrm{C}=\mathrm{O}\right)$, 2.85 (t, 2H, $\left.\mathrm{CH}_{2}-\mathrm{N}\right), 3.44$ (s, 2H, N- $\left.\mathrm{CH}_{2}-\right), 4.09$ (t, $\left.4 \mathrm{H}, \mathrm{CH}_{2}-\mathrm{O}\right)$. 
Synthesis of CPT-PAE-MPEG. CPT-PAE-MPEG copolymer was prepared via click chemistry. Click chemistry is the joining reaction between an alkyne and $\mathrm{N}_{3}$ in the presence of copper catalysis utilizing 1.3-dipolar cycloaddition.

CPT-PAE-MPEG was synthesized using a mixture of MPEG-N $\mathrm{N}_{3}$ and CPT- $\mathrm{N}_{3}$ at two ratios of MPEG : CPT (60:40 and $\left.80: 20\right)$.

To synthesize CPT-PAE-MPEG copolymer at a ratio of $80: 20$, PAE $(19.7 \mathrm{mg}, 0.06 \mathrm{mmol})$ and CPT-N $3(5.58 \mathrm{mg}, 0.012 \mathrm{mmol})$ were dissolved in $5 \mathrm{ml}$ anhydrous DMF. Then $\mathrm{CuBr}(3.5 \mathrm{mg}$, $0.024 \mathrm{mmol}$ ) as the catalyst and triethylamine were added to the mixture (1.08 $\mathrm{mg}, 0.024 \mathrm{mmol})$. This mixture was stirred at room temperature for $48 \mathrm{~h}$ under nitrogen atmosphere. Then, MPEG-N ${ }_{3}$ (98.68 mg, $0.048 \mathrm{mmol}$ ) was added, and the reaction was stirred under the condition described above. After $48 \mathrm{~h}$, the excess amount of MPEG-N ${ }_{3}$ (115 mg, $0.055 \mathrm{mmol}$ ) was added to consume unreacted acetylene group of PAE, and it was stirred for further $48 \mathrm{~h}$. Finally, the reaction mixture was centrifuged at $7000 \mathrm{rpm}$ for $20 \mathrm{~min}$. The solution was separated and precipitated with cold diethyl ether, and it was dried with the evaporation of the solvent to obtain viscous yellow oil. The finished product was purified by dialysis (cut-off $3500 \mathrm{Da}$ ) with buffer solution ( $\mathrm{pH} \mathrm{7.4)}$ for $48 \mathrm{~h}$ at $4{ }^{\circ} \mathrm{C}$. The final CPT-PAE-MPEG copolymer was synthesized with yield of $60 \%$, and the structure of copolymer was proved by FT-IR and ${ }^{1} \mathrm{H}$ NMR data. The reaction is shown in Fig. $1 \mathrm{~F}$.

To synthesize CPT-PAE-MPEG copolymer with ratio of 60 : 40, PAE (9.85 mg, $0.03 \mathrm{mmol}$ ), CPT-N 3 (11.16 mg, 0.024 $\mathrm{mmol}) \mathrm{CuBr}$ (1.75 mg, $0.012 \mathrm{mmol}$ ) and MPEG-N 3 (76.14 mg, $0.036 \mathrm{mmol})$ were added to DMF $(5 \mathrm{ml})$. The reaction was allowed to continue in different steps similar to the reaction of $80: 20$. The final CPT-PAE-MPEG copolymer was synthesized with yield of $50 \%$.

FT-IR (KBr): $\nu_{\max }\left(\mathrm{cm}^{-1}\right)=3458(-\mathrm{N}-\mathrm{H}), 3007(=\mathrm{C}-\mathrm{H}$, ring), 2927 and $2857(-\mathrm{C}-\mathrm{H}), 1732(\mathrm{C}=\mathrm{O}$, ester of PAE and CPT $), 1748$ $(\mathrm{C}=\mathrm{O}$ of lactone of $\mathrm{CPT}), 1656(\mathrm{C}=\mathrm{O}$ of amide of CPT) 1562 and 1452 ( $\mathrm{C}=\mathrm{C}$ ring, of $\mathrm{CPT}), 1624(\mathrm{C}=\mathrm{N}$ of $\mathrm{CPT}), 1357$ (C-N of CPT and PAE), 1230 and 1149 (C-O, ring of CPT), 1118 (C-O).

${ }^{1} \mathrm{H}$ NMR (400 MHz; DMSO-d $\left.\mathrm{d}_{6}\right): \delta=1.17,1.26,1.39(\mathrm{~m}, 12 \mathrm{H}$, $\mathrm{CH}_{2}$, of PAE chine), $2.33\left(\mathrm{t}, 2 \mathrm{H}, \mathrm{CH}_{2} \mathrm{C}=\mathrm{O}\right.$, of PAE), $2.56(\mathrm{t}, 2 \mathrm{H}$, $\mathrm{CH}_{2}-\mathrm{N}$, of polymer), 0.95 and $1.7\left(\mathrm{~m}, 4 \mathrm{H}, \mathrm{CH}_{2}\right.$, of CPT- $\mathrm{N}_{3}$ chine) $2.95\left(\mathrm{t}, 2 \mathrm{H}, \mathrm{CH}_{2}-\mathrm{N}_{3}\right.$, of CPT-N $\mathrm{N}_{3}$ chine), 2.31 (t, $2 \mathrm{H}, \mathrm{CH}_{2}-\mathrm{C}=\mathrm{O}$, of CPT- $\mathrm{N}_{3}$ chine), $3.44\left(\mathrm{~s}, 2 \mathrm{H},-\mathrm{N}-\mathrm{CH}_{2}\right.$-teryazol ring), $3.82(\mathrm{t}, 4 \mathrm{H}$, $-\mathrm{O}-\mathrm{CH}_{2}-\mathrm{CH}_{2}-\mathrm{O}-$, of PEG-N $\left.{ }_{3}\right) 4.09$ (t, 4H, $\mathrm{CH}_{2}-\mathrm{O}$, of PAE), 7.03 $\left(1 \mathrm{H}, \mathrm{CH}\right.$, of teryazol ring), 6.1-7.80 (m, 6H, CH, of CPT- $\mathrm{N}_{3}$ ring).

\section{Copolymer characterization}

FT-IR (fourier transform infrared spectroscopy). FT-IR spectra of compounds were obtained with FT-IR spectroscopy (IR prestige-21, Shimadzu Co., Japan) in the spectral range of $400-4000 \mathrm{~cm}^{-1}$ at a resolution of $4 \mathrm{~cm}^{-1}$ and room temperature using $\mathrm{KBr}$ disc.

${ }^{1}$ H NMR. ${ }^{1} \mathrm{H}$ NMR spectra were obtained on a Broker MSI-400 at $400 \mathrm{MHz}$. Chemical shifts are in part per million (ppm) downfield from TMS as an internal standard, and samples were dissolved in DMSO- $\mathrm{d}_{6}$ for analysis.
Critical micelle concentrations of CPT-PEA-MPEG copolymer. The critical micelle concentration (CMC) was measured with the fluorescent method and using Nile Red as a fluorescent indicator with a concentration of $2.5 \times 10^{-8} \mathrm{M}$. For the CMC study, CPT-PEA-MPEG micelles at MPEG : CPT ratio of $60: 40$ and $80: 20$ were prepared with serial dilution $\left(0.25-2.47 \times 10^{-7}\right.$ and $0.05-1.95 \times 10^{-5} \mathrm{mg} \mathrm{ml}^{-1}$, respectively) using distilled water. The obtained solutions were sonicated for $30 \mathrm{~min}$, and then the emission spectra of Nile Red were recorded at $512 \mathrm{~nm}$ (the exciting wavelength was $482 \mathrm{~nm}$, and the emission wavelength range were 500-650 nm). The fluorescent intensity was measured using a fluorescence spectrophotometer (PerkinElmer, LS-45, U.K).

Molecular weight determination. The molecular weight of the polymer was measured by static light scattering (SLS) technique using Zetasizer (Nano-ZS, Malvern Instruments Ltd., Worcestershire, UK). For this step, six different concentrations of solutions (0.01-0.06 $\mathrm{mg} \mathrm{ml}^{-1}$ ) were prepared, and molecular weights were recorded using the Malvern supplied molecular weight operating procedure. Toluene (the solvent for polymer) was used as the reference.

\section{Micelles characterization}

Preparation of nanomicelles. The nanomicelles were prepared by microemulsion technique. $1.25 \mathrm{mg}$ of the synthesized copolymer was added to $2 \mathrm{ml}$ of DCM at room temperature. Then, the organic phase was added to $5 \mathrm{ml}$ of DI water (aqueous phase) under rapid stirring condition.

The obtained emulsion was sonicated with a $20 \mathrm{kHz}$ sonicator (GM 2070, Bandelin, Germany) for $2 \mathrm{~min}$ at $70 \%$ power, and then it was stirred at room temperature to evaporate DCM.

Measurement of particle size. The mean particle size (Zaverage) of nanomicelles was measured using Zeta seizer (ZS300, Malvern Co., UK) at room temperature. For this step, the solution was prepared, and it was filtered with $400 \mathrm{~nm}$ filter to remove any dust and impurity. The average size of the nanomicelles was determined in two different MPEG : CPT ratios (80:20 and $60: 40)$.

Transmission electron microscope. The morphology of nanomicelles was studied using a Transmission Electron Microscope (TEM, Zeiss - EM10C $-80 \mathrm{kV}$, Germany). For the preparation of the sample, a drop of micelles at the ratio of $60: 40(0.25 \mu \mathrm{g}$ $\mathrm{ml}^{-1}$ ) was placed on a carbon-coated copper grid and then dried under air atmosphere at room temperature.

Yield of CPT conjugation. The amount of conjugated CPT in CPT-PEA-MPEG micelles was determined using UV spectrophotometer (Shimadzu, 1240 UV-Vis., Japan). Briefly, $1 \mathrm{mg}$ of CPT-PEA-MPEG micelles at MPEG : CPT ratio of $60: 40$ was dissolved in $600 \mu \mathrm{l}$ of EtOH, and then $400 \mu \mathrm{l}$ of distilled water was added to the solution. The absorption of the diluted solution was determined by UV spectrophotometer at $370 \mathrm{~nm}$. The calibration curve was prepared for the quantification of CPT at the CPT concentrations of 439, 219, 109, 54 and $27 \mu \mathrm{g} \mathrm{ml}{ }^{-1}$ with a correlation coefficient of $R^{2}=0.9980$. The yield of CPT conjugation was obtained as the mass ratio between the conjugated amount of CPT in micelles and the initial amount of drug used in the preparation. 
Release study. The in vitro release of CPT-PEA-MPEG micelles with MPEG : CPT ratio of 60 : 40 was measured in PBS (phosphate buffer solution, $0.01 \mathrm{~N})$ containing EtOH $(3 \%, \mathrm{v} / \mathrm{v})$ at $37{ }^{\circ} \mathrm{C}$. Four mg of micelles was suspended in $4 \mathrm{ml}$ of PBS at $\mathrm{PH}$ 7.4 or 5.8. Then, the micelles solution was placed into a dialysis bag (molecular weight cut-off 8000), and the dialysis bag was plunged in $40 \mathrm{ml}$ of PBS containing $3 \% \mathrm{v} / \mathrm{v}$ EtOH and $0.1 \% \mathrm{w} / \mathrm{v}$ $\mathrm{NaN}_{3}$ (to prevent bacteria and fungi growth) at $\mathrm{pH} 7.4$ or 5.8. The temperature was kept constant at $37{ }^{\circ} \mathrm{C}$ with horizontal shaking at $120 \mathrm{rpm}$ in a shaker (NB-205, N-Biotek, Korea) for 11 days. At the designated time intervals, $2 \mathrm{ml}$ of release medium was withdrawn, and the amount of drug release for samples was assessed by UV-Vis spectrophotometer at $370 \mathrm{~nm}$. The withdrawn medium was replenished with fresh release medium. ${ }^{25}$

In vitro cytotoxicity tests. In vitro cytotoxicity test was performed using HT29 cell line were obtained from Pasteur Institute (Tehran, Iran). The cells were cultured in RPMI-1640 containing $10 \%$ FBS and penicillin-G/streptomycin solution (100 mg ml $\mathrm{ml}^{-1}-100 \mathrm{U} \mathrm{ml}^{-1}$ ). These cells were placed in an incubator under conditions of $95 \%$ moisture, $5 \% \mathrm{CO}_{2}$, and temperature of $37.5{ }^{\circ} \mathrm{C}$ for $24 \mathrm{~h}$. Nanomicelles with concentrations in the range of $0.0062-0.1 \mathrm{mg} \mathrm{ml}^{-1}$ were added to microplates. The cell survival was measured using 3-(4,5dimethylthiazol-2-yl)-2,5-diphenyl tetrazolium bromide (MTT) test. After $48 \mathrm{~h}, 20 \mu \mathrm{l}$ of MTT solution $\left(0.1 \mathrm{mg} \mathrm{ml}^{-1}\right)$ was added to microplates, and the cells were incubated for $3 \mathrm{~h}$. Then, the content of wells was dissolved in DMSO (150 $\mu$ l per well). Formazan product was detected by measuring absorbance with an ELISA plate reader (BioTek, H1M, USA) at a test wavelength of $540 \mathrm{~nm}$ and a reference wavelength of $630 \mathrm{~nm}$ to obtain sample signal as the following formulation:

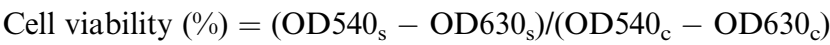

$$
\begin{aligned}
& \times 100
\end{aligned}
$$

where $\mathrm{s}$ is sample and $\mathrm{c}$ is control.

\section{Results and discussion}

\section{Synthesis and characterization of polymers}

MPEG-Tos, MPEG-N ${ }_{3}$, CPT-N ${ }_{3}$, PAE and CPT-PAE-MPEG copolymers were synthesized, and their structures were confirmed by FT-IR and ${ }^{1} \mathrm{H}$ NMR. The yield and changing the color of products were reported in each part. The characterization of each product was studied separately.

\section{FT-IR spectroscopy analysis}

The FT-IR spectrum of the prepared PEG-Tos indicated that the characteristic peak at 1176 and $1346 \mathrm{~cm}^{-1}$ were related to symmetrical and asymmetrical stretching vibrations of $\mathrm{S}=\mathrm{O}$. The $\mathrm{C}=\mathrm{C}$ stretching vibrations of the aromatic ring was observed at 1597 and $1465 \mathrm{~cm}^{-1}$, and the peak at $3057 \mathrm{~cm}^{-1}$ was related to the $\mathrm{C}-\mathrm{H}$ stretching vibration of the aromatic ring. Also, the broad peak of $\mathrm{OH}$ group of PEG at $3417 \mathrm{~cm}^{-1}$ was disappeared. These results confirmed the presence of tosyl group. The spectrum of PEG- $\mathrm{N}_{3}$ revealed the characteristic peak of $\mathrm{N}_{3}$ stretching vibrations at $2100 \mathrm{~cm}^{-1}$ in the $\mathrm{PEG}-\mathrm{N}_{3}$, and the omitting of PEG-Tos peaks at 1570 and $1176 \mathrm{~cm}^{-1}$ (relating to benzyl ring and $\mathrm{S}=\mathrm{O}$, respectively) confirmed the presence of $\mathrm{N}_{3}$.

PAE was synthesized by two monomers; propargylamine and 1,6-hexanediol diacrylate. The spectrum of propargylamine showed the characteristic peaks of $\mathrm{N}-\mathrm{H}$ primary amine stretching vibration and bending vibration of the propargyl at 3429, 3600 and $1635 \mathrm{~cm}^{-1}$. Also, the sharp peak located at $2150 \mathrm{~cm}^{-1}$ identified the acetylene stretching vibration, and the peak at $3290 \mathrm{~cm}^{-1}$ indicated the symmetrical C-H stretching of acetylene group of the propargyl. The 1,6-hexanediol diacrylate spectrum showed the characteristic of $\mathrm{C}-\mathrm{H}$ alkenes stretching vibration peak at $3105 \mathrm{~cm}^{-1}$, and the peak at $1635 \mathrm{~cm}^{-1}$ indicated the $\mathrm{C}=\mathrm{C}$ alkenes stretching vibration. The synthesized PAE showed the $\mathrm{C}-\mathrm{H}$ alkenes stretching vibration peak at $3287 \mathrm{~cm}^{-1}$, and the sharp peak at $2102 \mathrm{~cm}^{-1}$ identified $\mathrm{C} \equiv \mathrm{C}$ stretching in propargylamine. Also, the peak at $3444 \mathrm{~cm}^{-1}$ was characteristic of $\mathrm{N}-\mathrm{H}$ stretching vibration of the second amine, and the peak at $3051 \mathrm{~cm}^{-1}$ could be related to $\mathrm{C}-\mathrm{H}$ alkene stretching vibration. The characteristic peak of $\mathrm{C}-\mathrm{H}$ alkenes stretching vibration at $3105 \mathrm{~cm}^{-1}$ and the peak of $\mathrm{C}=\mathrm{C}$ alkenes stretching vibration at $1635 \mathrm{~cm}^{-1}$ were omitted in the polymer spectrum, which confirmed the reaction between 1,6-hexanediol diacrylate and propargylamine.

The esterification between $\mathrm{OH}$ group of CPT and the carboxylic acid group of 6-azidohexanoic acid resulted in CPT$\mathrm{N}_{3}$. The spectrum of 6-azidohexanoic acid showed the broad peak of $\mathrm{OH}$ stretching vibration in the range of $2400-3600 \mathrm{~cm}^{-1}$, and the sharp peak of $\mathrm{C}=\mathrm{O}$ stretching vibration of carboxylic acid at $1708 \mathrm{~cm}^{-1}$. Also, this spectrum identified a sharp peak of - the $\mathrm{N}_{3}$ stretching vibration of 6-azidohexanoic acid at $2100 \mathrm{~cm}^{-1}$, and the spectrum of CPT showed a broad peak of $\mathrm{OH}$ stretching vibration at $3433 \mathrm{~cm}^{-1}$ while the spectrum of the CPT- $\mathrm{N}_{3}$ indicated a peak observed at $1747 \mathrm{~cm}^{-1}$ region for the ester carbonyl stretching vibration. The presence of this peak and disappearing peak at $3433 \mathrm{~cm}^{-1}$ confirmed the esterification and the presence of CPT- $\mathrm{N}_{3}$.

We applied the click chemistry between acetylene group of PAE and $\mathrm{N}_{3}$ group of CPT- $\mathrm{N}_{3}$ and MPEG- $\mathrm{N}_{3}$ to synthesize CPTPAE-MPEG. The FT-IR spectrum of CPT-PAE-MPEG were indicated the peaks of the $\mathrm{CH}_{2}$ and $\mathrm{CH}_{3}$ symmetric, and asymmetric stretching vibrations from 2854 to $2927 \mathrm{~cm}^{-1}$ and a weak vinyl $\mathrm{C}-\mathrm{H}$ stretching vibration peak appeared at $3007 \mathrm{~cm}^{-1}$. The carbonyl bands from ester group of PAE, lactone and amide group of CPT were indicated at 1732, 1748 and $1656 \mathrm{~cm}^{-1}$, respectively. The peaks at 1562 and $1452 \mathrm{~cm}^{-1}$ were attributed to the symmetrical $\mathrm{C}=\mathrm{C}$ stretching of aromatic ring group of $\mathrm{CPT}$, and the peak at $1624 \mathrm{~cm}^{-1}$ was corresponded to the $\mathrm{C}=\mathrm{N}$ stretching vibration of CPT, although the peak at $1624 \mathrm{~cm}^{-1}$ was overlapped by the peak of $\mathrm{C}=\mathrm{C}$ vinyl stretching vibration of triazole ring. The peak at $1118 \mathrm{~cm}^{-1}$ was corresponded to $-\mathrm{C}-\mathrm{O}-$ of MPEG. Furthermore, the peaks of $\mathrm{C} \equiv \mathrm{C}$ (at $2150 \mathrm{~cm}^{-1}$ region) and $\equiv \mathrm{C}-\mathrm{H}\left(3290 \mathrm{~cm}^{-1}\right.$ region) related to $\mathrm{PAE}$ and peak of $\mathrm{N}_{3}$ (at $2100 \mathrm{~cm}^{-1}$ region) corresponding to PEG-N $\mathrm{N}_{3}$ and CPT- $\mathrm{N}_{3}$ were disappeared in CPT-PAE-MPEG spectrum synthesis of the copolymer. 


\section{${ }^{1}$ H NMR spectroscopy analysis}

${ }^{1} \mathrm{H}$ NMR data for 6-bromohexanoic acid indicated the peaks at $3.5,2.21$ and $11.89 \mathrm{ppm}$, which were respectively attributed to the protons of the $-\mathrm{CH}_{2} \mathrm{Br},-\mathrm{CH}_{2} \mathrm{COOH}$ and $-\mathrm{COOH}$. The spectrum of 6-azidohexanoic acid revealed the peaks at 3.32, 2.54 and $11.88 \mathrm{ppm}$ that were respectively related to protons of the $-\mathrm{CH}_{2} \mathrm{~N}_{3},-\mathrm{CH}_{2} \mathrm{COO}$ and $-\mathrm{COOH}$. These data confirmed the successful synthesis of 6-azidohexanoic acid. Then, the carboxylic acid group of 6-azidohexanoic acid was grafted into hydroxyl group of CPT. The characteristic peaks of CPT- $\mathrm{N}_{3}$ at 2.33 and $2.5 \mathrm{ppm}$ identified protons of the $-\mathrm{CH}_{2} \mathrm{COO}-\mathrm{CPT}$ and $-\mathrm{CH}_{2} \mathrm{~N}_{3}$ groups of 6-azidohexanoic, and the peak at $11.88 \mathrm{ppm}$ related to the proton of - $\mathrm{COOH}$ group was omitted. These peaks confirmed the conjugation of 6-azidohexanoic acid to CPT. Also, the peaks at 5.76-8.15 ppm assigned to the phenyl ring and protons of the double bend of CPT confirmed the presence of CPT in the structure. ${ }^{26}$ In the spectrum of MPEG, the identified a peck at $3.4 \mathrm{ppm}$ indicated the protons of ethylene group.

PAE showed the peak of $-\mathrm{CH}_{2} \mathrm{NH}-$ at $3.44 \mathrm{ppm}$ and the peak of methylene of propargylamine group at $3.69 \mathrm{ppm}$. The peak at 2.47 indicated protons of $-\mathrm{CH}_{2} \mathrm{COO}-$ and the peak at 4.08 identified protons of $-\mathrm{CH}_{2} \mathrm{OOC}-$ group. Also, the peak at $2.85 \mathrm{ppm}$ was characteristic of proton of propargylamine group $(-\mathrm{C} \equiv \mathrm{CH})$, the peak relating to the proton alkenes of 1,6 -hexanediol diacrylate group at around $6 \mathrm{ppm}$ was omitted. These results confirmed the synthesis of PAE from 1,6-hexanediol diacrylate and propargylamine. In the spectrum of CPT-PAEMPEG, the peaks relating to protons of $-\mathrm{O}-\mathrm{CH}_{2}-\mathrm{CH}_{2}-\mathrm{O}$ and $-\mathrm{OCH}_{3}$ of MPEG unit at 3.82 and $4.09 \mathrm{ppm}$, were observed, respectively. The peaks relating to protons of $\mathrm{C}-\mathrm{H}$ aromatic ring of CPT at 6.1-7.80 ppm were observed, and also the peak relating to the proton of $\mathrm{C}-\mathrm{H}$ double bond triazole ring at $7.03 \mathrm{ppm}$ was observed. The results of ${ }^{1} \mathrm{H}$ NMR spectra confirmed the synthesis of CPT-PAE-MPEG.

\section{Molecular weight analysis}

The molecular weight of PAE was evaluated with the Zetasizer Nano system. The molecular weight was obtained about $11.1 \mathrm{kD}$ which is similar to results obtained in other studies. The derivative of PAE containing secondary amine group had a molecular weight in around 6 to $10 \mathrm{kD} .^{27}$

\section{Characterization of micelles}

Particle size analysis and stability of nanomicelles. The particle sizes and PDI were analyzed for CPT-PAE-MPEG nanomicelles with different ratios of MPEG to CPT (60:40 and $80: 20$ ). The mean particle size of nanomicelles at ratios of $60: 40$ and $80: 20$ was $118.9 \pm 1.66$ and $166.6 \pm 26.79 \mathrm{~nm}$, and their PDIs were $0.108 \pm 0.014$ and $0.292 \pm 0.018$, respectively. The size and PDI of nanomicelles decreased with increasing the percentage of conjugated CPT. Increasing the degree of substitution increases the hydrophobicity and consequently forming a denser core, which could be the reason for decreasing the size of $60: 40 .^{28}$ The reduced trend of size in the hydro state in this study agrees with a similar study carried out by Yang et al. ${ }^{29}$ the higher percentage of the drug is, the higher hydrophobic interaction at the core of micelles is.
The results of stability of nanomicelles for ratios of $60: 40$ and $80: 20$ are shown in Fig. 2. At the ratio of $80: 20$, not only particle size showed enhancement during the time, but also standard deviation (S.D.) was significantly higher than that one at ratio $60: 40$. The lower S.D. is, the higher stability is. According to reasons above, the stability of $60: 40$ could be related to the formation of the denser core and lower CMC value. $^{28}$

Critical micelle concentrations of CPT-PAE-MPEG copolymer. The result of critical micelle concentrations (using Nile Red) is shown in Fig. 3. The critical micelle concentration (CMC) was $3.55 \times 10^{-5} \mathrm{mg} \mathrm{ml}^{-1}$ at ratio of $60: 40$ and $1.96 \times 10^{-4} \mathrm{mg} \mathrm{ml}^{-1}$ at ratio of $80: 20$.

Low CMC is one of the most important characters of nanomicelles for in vivo applications. Nanomicelles with lower CMC have enhanced stability in body fluids. The drug-loaded polymeric micelles with high CMC led to an infinite dilution in the bloodstream, which may cause the dissociation of the polymeric micelle and premature drug release. The inherent CMC values of polymeric micelles are influenced by the molecular weight of block copolymers, the hydrophobicity of hydrophobic block, as well as the block length and ratio of blocks. ${ }^{30}$ Increasing the CPT percentage leads to an increase in hydrophobic interaction at the core of micelles and causes facilitating the formation of nanomicelles. Inter-molecular interactions such as electrostatic interactions, chemical cross-linking, and hydrogen bonding can enhance stability. ${ }^{31}$

Morphology of nanomicelles. Transmission electron microscope image is shown in Fig. 4. Nanomicelles at the ratio of $60: 40$ have a spherical shape with a diameter of $78.4 \pm$ $33.18 \mathrm{~nm}$. The difference of nanomicelles size between DLS measurement compare to the size of nanomicelles in images of TEM is caused by hydrodynamic ratio role in the measured size of DLS method. Particle size blow than $200 \mathrm{~nm}$ is an ideal size for nanoparticular drug delivery systems. At physiological condition distribution of nanoparticles and drug conjugated macromolecules can be proportional to the blood content of tissues. At pathogenic condition of tumors, not only blood content of tissue is high but also permeability of endothelial barrier is higher than normal tissues and drainage of nanoparticles cannot happen by the lymphatic system. Therefore

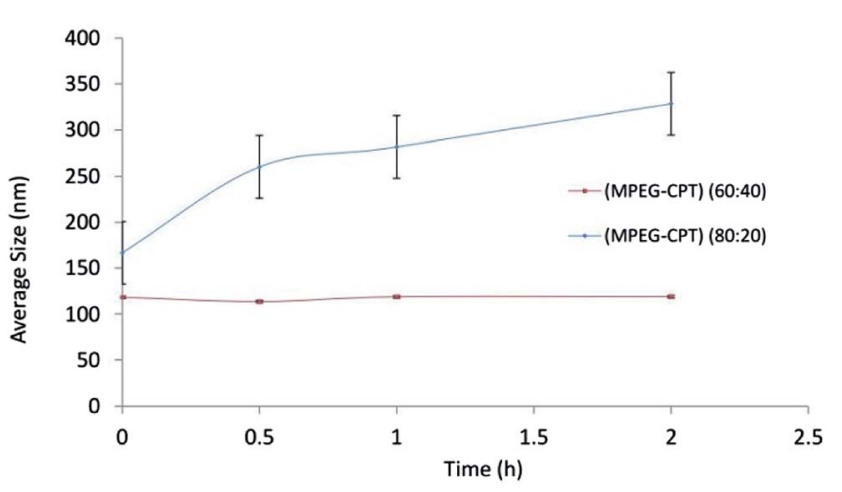

Fig. 2 The size stability of nanomicelles at ratios of $60: 40$ and $80: 20$. 


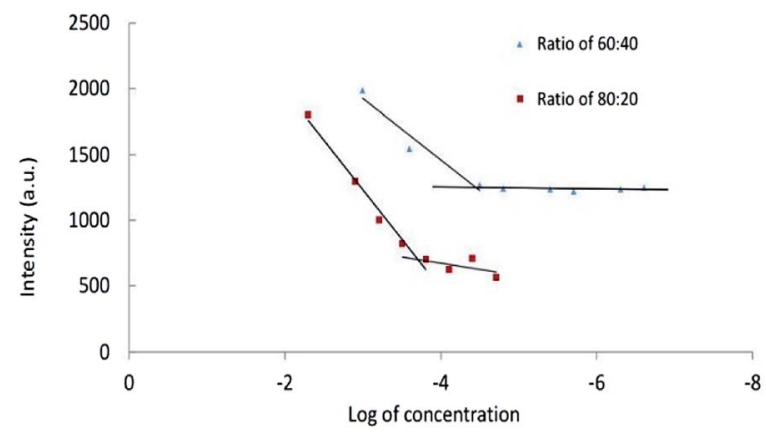

Fig. 3 The critical micelle concentrations of nanomicelles at different ratios of MPEG : CPT $(60: 40$ and $80: 20)$.

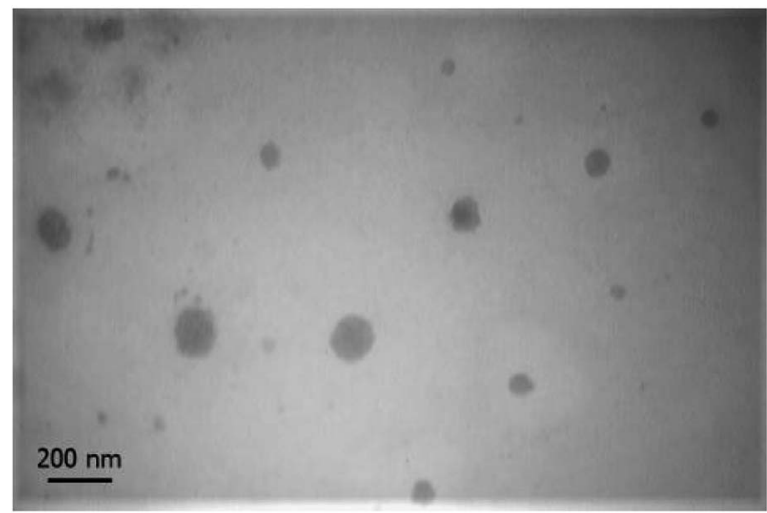

Fig. 4 TEM image of nanomicelles at ratio of $60: 40$ in $20000 \times$ magnification.

CPT-PAE-MPEG nanomicelles can be deposit into a tumor by enhanced permeation and retention (EPR) effect. On the other hand, low solubility and low blood protein binding of camptothecin cause its deposition in tissues immediately upon release and a long half-life in tumors.

The yield of drug conjugation and release analysis. The amount of conjugated CPT in CPT-PEA-MPEG micelles at ratio $60: 40$ was calculated using a UV-Vis spectrophotometer at $370 \mathrm{~nm}$. The absorbance band of solutions was recorded, and the calibration curve of CPT was prepared. The average percentage of conjugated CPT in CPT-PEA-MPEG micelles base on the initial amount of CPT was $66.52 \% \pm 0.06145$.

The release curve of CPT from CPT-PEA-MPEG micelles in 11 days is illustrated in Fig. 5. It showed that approximately 87 and $69 \%$ of CPT were released in 11 days at $\mathrm{pH} 5.8$ and 7.4, respectively. In the first day, CPT-PEA-MPEG micelles released about 26.1 and $17.81 \%$ of CPT at pH 5.8 and 7.4, respectively. The release rate of CPT from CPT-PEA-MPEG micelles gradually increased in 6 days and reached to 76.51 and $58.01 \%$ at $\mathrm{pH} 5.8$ and 7.4, respectively. These results indicated that CPT-PEAMPEG micelles showed a distinguished $\mathrm{pH}$-dependent drug release profiles. At pH 5.8, hydrolyze of ester bonds between drug and polymer is catalysed, and the release of CPT was faster. Therefore, acidic $\mathrm{pH}$ of the tumor can potentially trigger the rapid release of CPT at the tumor tissue.

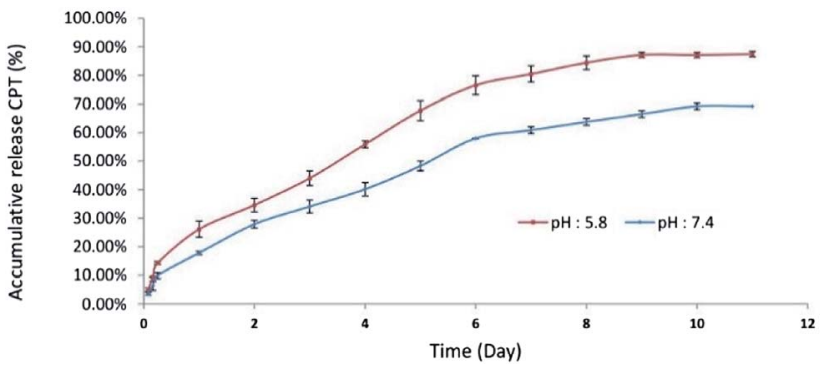

Fig. 5 Cumulative release of CPT from CPT-PEA-MPEG micelles at $\mathrm{pH}$ 5.8 and $\mathrm{pH} 7$, and $37^{\circ} \mathrm{C}$.

In vitro cytotoxicity study. In human tumor cell cytotoxicity assays, CPT and CPT derivatives demonstrated the ability for topoisomerase II inhibition and were highly cytotoxic to HT29 colon tumor cells. ${ }^{32}$ The HT29 cell line was incubated with different concentrations $(0.1,0.05,0.025,0.0125,0.065 \mathrm{mg}$ $\mathrm{ml}^{-1}$ ) of CPT-PAE-MPEG nanomicelles at $60: 40$ and $80: 20$ ratios of MPEG to CPT for $48 \mathrm{~h}$ and the cytotoxicity was assessed using MTT method (Fig. 6). The results revealed that nanomicelles at the ratio of $60: 40$ have higher cytotoxicity compared to nanomicelles at a ratio of $80: 20$. The $\mathrm{IC}_{50}$ was $0.1 \mathrm{mg} \mathrm{ml}^{-1}$ of nanomicelles for the ratio of $60: 40$. The greater cytotoxicity of $60: 40$ was attributed to its higher percentage of CPT. In the previous studies by other researchers, micelles of MPEG modified PAE as drug delivery systems have been used as a promising carrier to increase the efficacy of anti-cancer therapy with no inherent therapeutic effect. ${ }^{33}$ The novel PAE synthesized in this study not only shows an inherent cytotoxic effect but also can be potentially used as a carrier of other anticancer drugs. Clinical studies approved that combination therapy can reduce the risk of drug resistance and improved chemotherapy. Also, it had been proved that the concentration of polymer-drug conjugates in the tumor could reach 10-100 times higher than that for free drug. ${ }^{34}$ On the other hand, this polymeric micelle increases solubility, stability, and bioavailability of CPT. The cytotoxic activity of CPT depends on its structure. With conjugating CPT to PAE, the lactone ring can be stabilized. Camptothecin is an active anti-tumor drug, containing $\alpha$-hydroxy- $\delta$-lactone ring moiety. The intrinsic instability of CPT arises from the rapid hydrolysis of this ring in basic or neutral media, to give the open carboxylate form, which is essentially inactive. The reaction is reversible, and the lactone

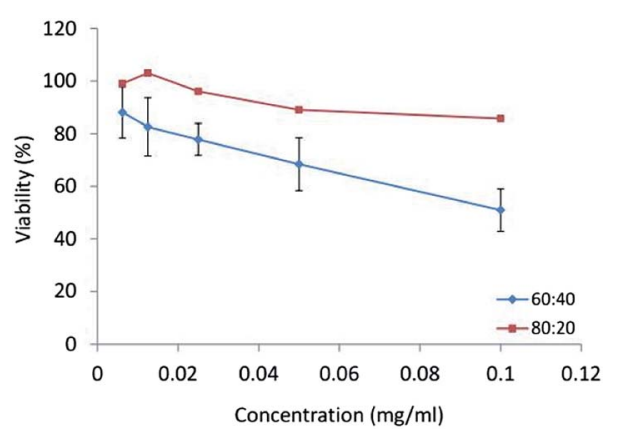

Fig. 6 The cytotoxicity of nanomicelles at different ratios of MPEG : CPT (60 : 40 and $80: 20$ ) on HT-29 cell line. 
form predominates only at acidic $\mathrm{pH}$. Pharmacokinetic studies have shown this $\mathrm{pH}$-dependent hydrolytic equilibrium to be shifted toward the carboxylate form in plasma, in a speciesdependent manner which the in vivo and in vitro biological activities of camptothecin are significantly greater for the lactone than those for the carboxylate form. Lactone form has a critical role in the passive diffusion of the drug into cancer cells as well as for successful interaction with the pharmacological target. ${ }^{35}$ It has been approved that the conjugation of CPT from its 20-OH group to a macromolecule, e.g., PEG, poly(Lglutamic acid), starch and chitosan can enhance the solubility of the lactone ring and reduce the propensity for opening the ring. ${ }^{12,36-38}$

Regarding the obtained results, CPT is utilized as a constituent of nanomicelle caused inherent anti-cancer activity of micelles. On the other hand, prepared nanomicelles can be used as a proper carrier for other anti-cancer drugs. Co-delivery of two anticancer agents reduces the complexity of combination by enabling a better time, location, and dosage control and also results in synergistic effects. ${ }^{39}$ According to these reasons, we achieved an advantageous formulation which can be inherently used for cancer treatment and can act as a proper carrier for anti-cancer drugs.

\section{Conclusion}

CPT is an active anti-tumor drug, effective on a wide range of tumors, e.g., lung, breast, stomach, bladder, melanoma and ovary cancers. The therapeutic applications of CPT have been limited due to its instability at neutral $\mathrm{pH}$, low solubility in aqueous medium and unwanted toxicity. In the present study, we designed a new PAE with high CPT conjugation efficiency and also, MPEG was used to enhance the stability and half-life of the carrier system.

The nanomicelles at two different ratios of MPEG : CPT (60:40 and $80: 20)$ were prepared. The synthesis was confirmed with FT-IR and ${ }^{1} \mathrm{H}$ NMR. Microemulsion method was employed to prepare the nanomicelles. The CMC, particle size analysis, surface charge, and transmission electron microscope imaging were performed. According to the results, for nanomicelles with a ratio of $60: 40$, the mean particle size was 118.9 $\pm 0.96 \mathrm{~nm}$ and the critical micelle concentration was $3.55 \times$ $10^{-5} \mathrm{mg} \mathrm{ml}^{-1}$. In vitro cytotoxicity test was performed on HT29 cell line and the $\mathrm{IC}_{50}$ was achieved for $0.1 \mathrm{mg} \mathrm{ml} \mathrm{m}^{-1}$ of nanomicelles at MPEG : CPT ratio of $60: 40$. The results of this study showed that the CPT-PAE-MPEG nanomicelles at the ratio of $60: 40$ could be a proper choice to improve the physiochemical properties of CPT and enhance its therapeutic efficacy. Base of our knowledge it is the first time that camptothecin conjugated PAE-MPEG is synthesized and used for the preparation of nanomicelles with intrinsic anticancer effect and potential capacity to loading another anticancer drug with the purpose of dual drug delivery.

\section{Conflicts of interest}

There are no conflicts to declare.

\section{Acknowledgements}

The authors gratefully acknowledge the Research Council of Kermanshah University of Medical Sciences (Grant Number: 92135) for the financial support. This work was performed in partial fulfillment of the requirements for Pharm. D of Fatemeh Rahmati, School of Pharmacy, Kermanshah University of Medical Sciences, Kermanshah, Iran.

\section{References}

1 K. Cho, X. Wang, S. Nie and D. M. Shin, Clin. Cancer Res., 2008, 14, 1310-1316.

2 D. Peer, J. M. Karp, S. Hong, O. C. Farokhzad, R. Margalit and R. Langer, Nat. Nanotechnol., 2007, 2, 751-760.

3 M. K. Pratten, J. B. Lloyd, G. Hörpel and H. Ringsdorf, Macromol. Chem. Phys., 1985, 186, 725-733.

4 K. Kataoka, A. Harada and Y. Nagasaki, Adv. Drug Delivery Rev., 2001, 47, 113-131.

5 W. Xu, P. Ling and T. Zhang, J. Drug Delivery, 2013, 2013.

6 T. Kishida, H. Asada, Y. Itokawa, K. Yasutomi, M. Shin-Ya, S. Gojo, F.-D. Cui, Y. Ueda, H. Yamagishi and J. Imanishi, Mol. Ther., 2003, 8, 738-745.

7 F. Liu, L. M. Shollenberger and L. Huang, The FASEB journal, 2004, 18, 1779-1781.

8 N. Cao, D. Cheng, S. Zou, H. Ai, J. Gao and X. Shuai, Biomaterials, 2011, 32, 2222-2232.

9 T. K. Endres, M. Beck-Broichsitter, O. Samsonova, T. Renette and T. H. Kissel, Biomaterials, 2011, 32, 7721-7731.

10 X.-B. Xiong and A. Lavasanifar, ACS Nano, 2011, 5, 52025213.

11 M. Khan, Z. Y. Ong, N. Wiradharma, A. B. E. Attia and Y. Y. Yang, Adv. Healthcare Mater., 2012, 1, 373-392.

12 R. Tahvilian, B. Tajani, K. Sadrjavadi and A. Fattahi, Int. J. Biol. Macromol., 2016, 92, 795-802.

13 B. Tajani, R. Tahvilian, S. Khazaei, K. S. Javadi and A. Fattahi, J. Rep. Pharm. Sci., 2015, 4, 1-11.

14 M. S. Kim, D. S. Lee, E.-K. Choi, H.-J. Park and J.-S. Kim, Macromol. Res., 2005, 13, 147-151.

15 S. A. Meenach, C. G. Otu, K. W. Anderson and J. Z. Hilt, Int. J. Pharm., 2012, 427, 177-184.

16 D. M. Lynn and R. Langer, J. Am. Chem. Soc., 2000, 122, 10761-10768.

17 D. M. Lynn, D. G. Anderson, D. Putnam and R. Langer, J. Am. Chem. Soc., 2001, 123, 8155-8156.

18 A. W. Richter and E. Åkerblom, Int. Arch. Allergy Appl. Immunol., 1983, 70, 124-131.

19 X. Chen, S. McRae, S. Parelkar and T. Emrick, Bioconjugate Chem., 2009, 20, 2331-2341.

20 O. Altintas, B. Yankul, G. Hizal and U. Tunca, J. Polym. Sci., Part A: Polym. Chem., 2006, 44, 6458-6465.

21 E. K. Park, S. B. Lee and Y. M. Lee, Biomaterials, 2005, 26, 1053-1061.

22 H. Fan, J. Huang, Y. Li, J. Yu and J. Chen, Polymer, 2010, 51, 5107-5114.

23 B. Parrish and T. Emrick, Bioconjugate Chem., 2007, 18, 263267. 
24 B. D. Mather, K. Viswanathan, K. M. Miller and T. E. Long, Prog. Polym. Sci., 2006, 31, 487-531.

25 K. H. Min, J.-H. Kim, S. M. Bae, H. Shin, M. S. Kim, S. Park, H. Lee, R.-W. Park, I.-S. Kim and K. Kim, J. Controlled Release, 2010, 144, 259-266.

26 C.-Y. Li, C.-H. Lin and T.-S. Wu, Chem. Pharm. Bull., 2005, 53, 347-349.

27 I. K. Voets, A. de Keizer, M. A. Cohen Stuart, J. Justynska and H. Schlaad, Macromolecules, 2007, 40, 2158-2164.

28 A. Fattahi, M. Asgarshamsi, F. Hasanzadeh, J. Varshosaz, M. Rostami, M. Mirian and H. Sadeghi-aliabadi, J. Mater. Sci.: Mater. Med., 2015, 26, 119.

29 B. Yang, Y. Lv, J.-y. Zhu, Y.-t. Han, H.-z. Jia, W.-h. Chen, J. Feng, X.-z. Zhang and R.-x. Zhuo, Acta Biomater., 2014, 10, 3686-3695.

30 D. M. Brey, J. L. Ifkovits, R. I. Mozia, J. S. Katz and J. A. Burdick, Acta Biomater., 2008, 4, 207-217.
31 S. Kim, Y. Shi, J. Y. Kim, K. Park and J.-X. Cheng, Expert Opin. Drug Delivery, 2010, 7, 49-62.

32 M. J. Luzzio, J. M. Besterman, D. L. Emerson, M. G. Evans, K. Lackey, P. L. Leitner, G. McIntyre, B. Morton, P. L. Myers and M. Peel, J. Med. Chem., 1995, 38, 395-401.

33 G. Barratt, Cell. Mol. Life Sci., 2003, 60, 21-37.

34 J.-G. Shiah, M. Dvořák, P. Kopečková, Y. Sun, C. Peterson and J. Kopeček, Eur. J. Cancer, 2001, 37, 131-139.

35 T. G. Burke and Z. Mi, J. Med. Chem., 1994, 37, 40-46.

36 R. Bhatt, P. de Vries, J. Tulinsky, G. Bellamy, B. Baker, J. W. Singer and P. Klein, J. Med. Chem., 2003, 46, 190-193.

37 A. B. Fleming, K. Haverstick and W. M. Saltzman, Bioconjugate Chem., 2004, 15, 1364-1375.

38 G. Li, C. Cai, Y. Qi and X. Tang, Drug Delivery, 2016, 23, 277284.

39 R. Agarwal and S. B. Kaye, Nat. Rev. Cancer, 2003, 3, 502. 